\title{
Research on Real-time Monitoring of Urban Air Quality Based on Optimal Scale and Factor Analysis
}

\author{
Chun Chen ${ }^{1}$, a Xiang Gao ${ }^{2, b}$ Qian Mou ${ }^{3, \mathrm{c}}$ \\ ( ${ }^{1}$ Professor, Business School, Sichuan Normal University, Chengdu 610101, China) \\ ('Postgraduate student, Information School, the University of Sheffield, Sheffield S10 2TN, \\ the United Kingdom) \\ ('Postgraduate student, Business School, Sichuan Normal University, Chengdu 610101, China) \\ achenchun@sina.comb2846857801@qq.com c1369053026@qq.com
}

\begin{abstract}
Keywords: Air quality; Optimal scale; Multivariate statistical analysis
Abstract. In this paper, based on the 190 monitored city data released by the China National Environmental Monitoring Center in 2018, the optimal scale and factor analysis methods were selected to conduct in-depth research and analysis of urban air quality. The study found that: PM2.5 has a serious impact on air quality, and PM10, ozone, SO2, and NO2 are important factors affecting air quality. At present, cities with good air quality include Sanya, Haikou, Zhanjiang, Maoming, Beihai, Zhuhai, Lhasa, Shenzhen, Heyuan, etc.; cities with severe air pollution include Texas, Tianjin, Zaozhuang, Linyi, Handan, Tangshan, and Hengshui. Finally, based on the conclusions of the study, we propose strategies for effective improvement and control of air pollution.
\end{abstract}

\section{Introduction}

With the rapid development of the industry and transportation industry in China, a large amount of toxic dust is discharged into the air, causing air pollution, affecting the ecological environment. How to effectively control air pollution and improve air quality has become a matter of high concern for people now. To improve air quality, it is necessary to first monitor urban air quality in real time and find causes of air pollution from initial sources so as to achieve targeted environmental management. At present, 190 cities have established thousands of air quality monitoring stations. They continuously monitor air quality in 24 hours and publish PM2.5, PM10, CO, NO2, SO2, and ozone in real time. This study is based on the domestic monitoring of air quality in real-time monitoring of 190 cities, using factor analysis and optimal standards for air quality evaluation and research, hoping to reduce air pollution, improve and promote the development of ecological cities in China.

\section{Factor Analysis and Optimal Scale Analysis}

\section{Data Selection and Processing}

The data is taken from the 190 monitored city released by the China Environmental Monitoring Center of the Ministry of Environmental Protection. The data is from the PM2.5 data network. The 190 cities' air quality ranking data and the number of days of compliance were selected and released in March 2018, and the number of days of compliance was split into excellent and good days. Table 1 shows the actual data of 190 monitoring urban air quality variables, among which the first seven data are urban air quality monitoring data, which are PM2.5, fine particles, PM10 suction particles, carbon monoxide, nitrogen dioxide, sulfur dioxide, Ozone 1 hour's average and ozone 8 hours' average. AQI is the air quality index, which is also commonly used by developed countries in the air quality evaluation standards. AQI uses the piecewise linear function to convert the monitoring data into calculations. Through the AQI size, international or domestic city rankings can be obtained, and AQIs can also be divided into several types of grades: $A Q I \leq 50$ when the air quality is excellent, $50<\mathrm{AQI} \leq$ 100 is good, and then you can calculate the monthly or annual air quality days and good days. 
Table 1190 variables from monitored urban air quality

\begin{tabular}{cccc}
\hline $\begin{array}{c}\text { Name } \\
\text { Content }\end{array}$ & $\begin{array}{c}\text { PM2.5 } \\
\text { fine particles }\end{array}$ & $\begin{array}{c}\text { PM10 } \\
\text { suction particles }\end{array}$ & $\begin{array}{c}\text { CO } \\
\text { carbon monoxide }\end{array}$ \\
$\begin{array}{c}\text { Name } \\
\text { Content }\end{array}$ & $\begin{array}{c}\text { O3-8h } \\
\text { Ozone } 8 \mathrm{~h} \text { mean }\end{array}$ & $\begin{array}{c}\text { AQI } \\
\text { quality index }\end{array}$ & $\begin{array}{c}\text { EGDAYS } \\
\text { excellent days }\end{array}$ \\
Name & NO2 & SO2 & O3-1h \\
Content & nitrogen dioxide & sulfur dioxide & ozone 1h mean \\
& GDAYS & AQIR & CITY \\
Name & good days & ranking & cities \\
\hline
\end{tabular}

In order to facilitate the study, IBM SPSS Statistics 21 was used to test and standardize the air quality monitoring data of 7 cities. It was found that the data skewness was less than 1.5 and the absolute value of kurtosis was less than 4.5. Then the reliability of the standardized data is tested. The reliability statistic Cronbach's Alpha coefficient is 0.661 , which means that the corresponding observation variable is highly reliable, and it can be used for factor analysis or optimal scale analysis.

\section{Factor Analysis}

Multivariate statistical analysis includes factor analysis and optimal scale analysis. Factor analysis can regroup original variables into new unrelated several comprehensive main variables. These new main variables keep the original variable information as much as possible. Optimal Scaling provides a multivariate correspondence analysis method that display multiple variable information in a low-dimensional plan. In multivariate statistical analysis, they can be grouped according to the size of the original variable's relevance, so that the correlation within the group variable is higher, and the correlation between different groups of variables is lower. Each group is represented by an unobservable comprehensive variable. Factor analysis method can obtain correlation coefficient matrix by SPSS, obtain common factor, total factor variance, factor load matrix through variable correlation, then use factor rotation to obtain factor score, and finally calculate comprehensive score by variance contribution rate, and obtain city air quality rankings.

Table 2 shows the eigenvalue, variance contribution rate and cumulative contribution rate. According to the first two factors, the initial eigenvalue is greater than 1 , the cumulative variance contribution rate is $72.3 \%$, and the rotation square and cumulative variance contribution rate is $66.6 \%$. Therefore, the first two are selected. These factors have already evaluated the overall level of urban air quality.

Table 2 Eigenvalues, variance contribution rates and cumulative contribution rates

\begin{tabular}{l|l|l|l|r|r|r}
\hline Factor & \multicolumn{3}{|c|}{ Initial feature value } & \multicolumn{3}{|c}{$\begin{array}{r}\text { Rotation squared and } \\
\text { loaded }\end{array}$} \\
\hline & total & $\begin{array}{r}\text { variance } \\
\%\end{array}$ & $\begin{array}{r}\text { accumul } \\
\text { ation } \%\end{array}$ & total & $\begin{array}{r}\text { variance } \\
\%\end{array}$ & $\begin{array}{c}\text { accumula } \\
\text { tion \% }\end{array}$ \\
\hline 1 & 3.108 & 44.404 & 44.404 & 2.601 & 37.155 & 37.155 \\
\hline 2 & 1.953 & 27.905 & 72.308 & 2.061 & 29.446 & 66.601 \\
\hline 3 & .815 & 11.647 & 83.956 & & & \\
\hline
\end{tabular}

\begin{tabular}{c|c|c|c|c|c}
\hline Variable & $\begin{array}{c}\text { The first } \\
\text { factor }\end{array}$ & $\begin{array}{c}\text { The } \\
\text { second } \\
\text { factor }\end{array}$ & Variable & $\begin{array}{c}\text { The } \\
\text { first } \\
\text { factor }\end{array}$ & $\begin{array}{c}\text { The } \\
\text { second } \\
\text { factor }\end{array}$ \\
\hline $\mathrm{PM} 2.5$ & .891 & -.019 & $\mathrm{CO}$ & .353 & -.231 \\
\hline $\mathrm{PM} 10$ & .859 & .031 & $\mathrm{O}_{3}-1 \mathrm{~h}$ & -.074 & .997 \\
\hline $\mathrm{SO}_{2}$ & .742 & -.059 & $\mathrm{O}_{3}-8 \mathrm{~h}$ & -.071 & .996 \\
\hline $\mathrm{NO}_{2}$ & .618 & -.131 & & & \\
\hline
\end{tabular}

Table 3 shows the twiddle factor score matrix. The first factor's scores from high to low are PM2.5, $\mathrm{PM} 10, \mathrm{SO} 2, \mathrm{NO} 2$, and $\mathrm{CO}$. The second are $\mathrm{O} 3-1 \mathrm{~h}$ and $\mathrm{O} 3-8 \mathrm{~h}$, respectively. The variables with greater influence on air quality are PM2.5, PM10, SO2, NO2, and CO. In addition, the variable that have a greater impact on air quality is ozone. The analysis results are also basically consistent with the actual results. The scores FAC1_1 and FAC2_1 can be automatically calculated in the database.

Calculating the city air quality total score function based on the weight variance contribution factor corresponding to the rotation factor is:

$$
\mathrm{S} 1=\left(2.601 \mathrm{FAC} 1 \_1+2.061 \mathrm{FAC} 2 \_1\right) /(2.601+2.061)
$$


Table 4 lists the 190 city air quality index AQI rankings and comprehensive score rankings. We can see that the factor analysis comprehensive score ranking is basically the same as the national air quality index, indicating that the factor analysis comprehensive score is credible.

Table 4 City Air Quality Index AQI Ranking and Overall Score Ranking

\begin{tabular}{|c|c|c|c|c|c|c|c|c|c|c|c|}
\hline CITY & $\begin{array}{c}\text { AQIR } \\
\text { ranking }\end{array}$ & $\begin{array}{c}\text { Synthesis } \\
\text { ranking }\end{array}$ & CITY & $\begin{array}{c}\text { AQIR } \\
\text { ranking }\end{array}$ & $\begin{array}{c}\text { Synthesis } \\
\text { ranking }\end{array}$ & CITY & $\begin{array}{c}\text { AQIR } \\
\text { ranking }\end{array}$ & $\begin{array}{c}\text { Synthesis } \\
\text { ranking }\end{array}$ & CITY & $\begin{array}{c}\text { AQIR } \\
\text { ranking }\end{array}$ & $\begin{array}{c}\text { Synthesis } \\
\text { ranking } \\
\end{array}$ \\
\hline Sanya & 1 & 1 & Chaozhou & 49 & 52 & Hohhot & 97 & 167 & Jinchang & 145 & 104 \\
\hline Haikou & 2 & 4 & Zunyi & 50 & 54 & Rushan & 98 & 41 & Sanmenxia & 146 & 146 \\
\hline Zhanjiang & 3 & 6 & Wendeng & 51 & 33 & Wuxi & 99 & 116 & Xianyang & 147 & 153 \\
\hline Maoming & 4 & 11 & Zhang Qiu & 52 & 120 & Qingdao & 100 & 110 & Jintan & 148 & 78 \\
\hline North Sea & 5 & 5 & Hangzhou & 53 & 60 & Zhangjiagang & 101 & 100 & Qinhuangdao & 149 & 155 \\
\hline Zhuhai & 6 & 8 & Fushun & 54 & 72 & Changzhou & 102 & 125 & Suqian & 150 & 135 \\
\hline Yunfu & 7 & 29 & Wuhu & 55 & 50 & Jieyang & 103 & 57 & Huai'an & 151 & 83 \\
\hline Lhasa & 8 & 2 & Shanghai & 56 & 40 & Nanchong & 104 & 95 & Tongchuan & 152 & 75 \\
\hline Shenzhen & 9 & 17 & Shaoxing & 57 & 81 & Chifeng & 105 & 69 & Zhengzhou & 153 & 170 \\
\hline Heyuan & 10 & 22 & Haimen & 58 & 19 & Yantai & 106 & 108 & Pingdu & 154 & 111 \\
\hline Jiujiang & 11 & 32 & Wenzhou & 59 & 124 & Wafangdian & 107 & 53 & Qingyuan & 155 & 99 \\
\hline Zhoushan & 12 & 3 & Jiaxing & 60 & 55 & Suzhou & 108 & 98 & Jiayuguan & 156 & 51 \\
\hline Huizhou & 13 & 14 & Yiwu & 61 & 73 & Lacey & 109 & 71 & Jingzhou & 157 & 151 \\
\hline Meizhou & 14 & 18 & Zhuzhou & 62 & 96 & Yan'an & 110 & 148 & Weinan & 158 & 145 \\
\hline Qiqihar & 15 & 23 & Jin Hua & 63 & 47 & Yibin & 111 & 80 & Yangquan & 159 & 175 \\
\hline Shanwei & 16 & 10 & Kunshan & 64 & 77 & Taiyuan & 112 & 150 & Jiaozuo & 160 & 174 \\
\hline Nanchang & 17 & 31 & Zhangzhou & 65 & 36 & Yinchuan & 113 & 136 & Urumqi & 161 & 179 \\
\hline Guiyang & 18 & 24 & Panjin & 66 & 123 & Shizuishan & 114 & 117 & Kaifeng & 162 & 130 \\
\hline Yangjiang & 19 & 25 & Dongguan & 67 & 63 & Jinzhou & 115 & 142 & Beijing & 163 & 157 \\
\hline Daqing & 20 & 9 & Xiangtan & 68 & 92 & Hefei & 116 & 74 & Weifang & 164 & 152 \\
\hline Qujing & 21 & 26 & Taicang & 69 & 82 & Fuyang & 117 & 79 & Jining & 165 & 164 \\
\hline Zhongshan & 22 & 48 & Mianyang & 70 & 66 & Yue Yang & 118 & 119 & Heze & 166 & 138 \\
\hline Quanzhou & 23 & 16 & Harbin & 71 & 139 & Yancheng & 119 & 46 & Xi'an & 167 & 173 \\
\hline Fuzhou & 24 & 37 & Changsha & 72 & 102 & Benxi & 120 & 162 & Jinan & 168 & 165 \\
\hline Shantou & 25 & 27 & Guilin & 73 & 45 & Xining & 121 & 121 & Laiwu & 169 & 181 \\
\hline Kunming & 26 & 42 & Luzhou & 74 & 88 & Jiangyin & 122 & 126 & Cangzhou & 170 & 147 \\
\hline Yuxi & 27 & 61 & Changde & 75 & 76 & Luoyang & 123 & 156 & Pingdingshan & 171 & 154 \\
\hline Nanning & 28 & 59 & Linyi & 76 & 141 & Deyang & 124 & 112 & Liaocheng & 172 & 177 \\
\hline Xiamen & 29 & 20 & Liuzhou & 77 & 67 & Maanshan & 125 & 115 & Binzhou & 173 & 182 \\
\hline Jiangmen & 30 & 62 & Rongcheng & 78 & 12 & Nanjing & 126 & 128 & Yichang & 174 & 169 \\
\hline Lishui & 31 & 21 & Chengde & 79 & 101 & Lanzhou & 127 & 39 & Dongying & 175 & 180 \\
\hline Shaoguan & 32 & 90 & Huludao & 80 & 134 & Zhenjiang & 128 & 118 & Zibo & 176 & 187 \\
\hline Dandong & 33 & 35 & Zhuji & 81 & 70 & Yangzhou & 129 & 140 & Shouguang & 177 & 166 \\
\hline Panzhihua & 34 & 93 & Yixing & 82 & 103 & Shenyang & 130 & 160 & Anyang & 178 & 178 \\
\hline Mudanjiang & 35 & 43 & Wu Jiang & 83 & 84 & Jiaonan & 131 & 86 & Langfang & 179 & 176 \\
\hline Karamay & 36 & 15 & Zhangjiajie & 84 & 30 & Jurong & 132 & 131 & Dezhou & 180 & 171 \\
\hline Datong & 37 & 129 & Huzhou & 85 & 91 & Taizhou & 133 & 113 & Tianjin & 181 & 184 \\
\hline Zhangjiakou & 38 & 97 & Penglai & 86 & 68 & Lianyungang & 134 & 106 & Zaozhuang & 182 & 168 \\
\hline Foshan & 39 & 107 & Zigong & 87 & 58 & Rizhao & 135 & 127 & Linyi & 183 & 185 \\
\hline Chongqing & 40 & 89 & Changshu & 88 & 87 & Taian & 136 & 163 & Handan & 184 & 183 \\
\hline Ordos & 41 & 7 & Lin'an & 89 & 38 & Anshan & 137 & 159 & Tangshan & 185 & 189 \\
\hline Fuyang & 42 & 56 & Jiaozhou & 90 & 109 & Zhaoyuan & 138 & 114 & Hengshui & 186 & 172 \\
\hline Taizhou & 43 & 34 & Changzhi & 91 & 137 & Baotou & 139 & 143 & Baoding & 187 & 188 \\
\hline Jimo & 44 & 49 & Weihai & 92 & 13 & Xuzhou & 140 & 132 & Shijiazhuang & 188 & 186 \\
\hline Jilin & 45 & 44 & Changchun & 93 & 122 & Wuhan & 141 & 144 & Xingtai & 189 & 190 \\
\hline Ningbo & 46 & 28 & Dalian & 94 & 105 & Chengdu & 142 & 149 & Korla & 190 & 158 \\
\hline Yingkou & 47 & 65 & Zhaoqing & 95 & 133 & Laizhou & 143 & 94 & & & \\
\hline Guangzhou & 48 & 85 & Nantong & 96 & 64 & Baoji & 144 & 161 & & & \\
\hline
\end{tabular}

From Table 4, a few cities have different AQIR rankings and composite scores, and cities with higher comprehensive scores indicate that the comprehensive evaluation index of factor analysis is 
better than AQIR. The cities with high comprehensive scores are Erdos, Rongcheng, Weihai, Karamay, Zhangjiajie, etc. The cities with low overall scores include Jinchang, Yuxi, Jiangmen and Hohhot.

\section{Optimal Scale Analysis}

The study selects the optimal scale analysis in IBM SPSS Statistics 21, which provides homogeneity analysis, nonlinear correlation analysis and principal component analysis. It can do multiple correspondence analysis and will analyze multiple nonlinear variables in the low dimension. In order to facilitate the study with urban air quality, it is divided into three dimensions. Table 5 shows the scores of the principal components of variables. Analyzing the data in Table 5, PM2.5 and PM10 are the main factors affect air quality, and they are also important culprits that damage people's health.

Table 5 Principal Component Factor Scores for Variables

\begin{tabular}{ccccc}
\hline Variable & Factor 1 & Factor 2 & Factor 3 & Mean \\
\hline PM2.5 & .848 & .849 & .952 & .883 \\
PM10 & .924 & .944 & .674 & .847 \\
CO & .556 & .139 & .106 & .267 \\
NO2 & .798 & .785 & .866 & .817 \\
SO2 & .886 & .856 & .802 & .848 \\
O3-1h & .738 & .810 & .865 & .804 \\
O3-8h & .622 & .823 & .857 & .767 \\
Total amount & 5.372 & 5.206 & 5.122 & 5.233 \\
Total percentage & 76.743 & 74.370 & 73.168 & 74.761 \\
\hline
\end{tabular}

Figure 1 shows the three-dimensional difference map of urban air quality variables. Each box shows a two-dimensional difference map between a pair of main factors. It shows differences between the original value and the difference value, and differences between urban air quality variables. There is a big gap between $\mathrm{CO}$ and other variables, and $\mathrm{CO}$ has less influence on urban air quality; the other six variables are close to each other and have a stronger impact on urban air quality; $\mathrm{O} 3-1 \mathrm{~h}$ is close to O3-8h, and impacts of two variables on urban air quality are similar.

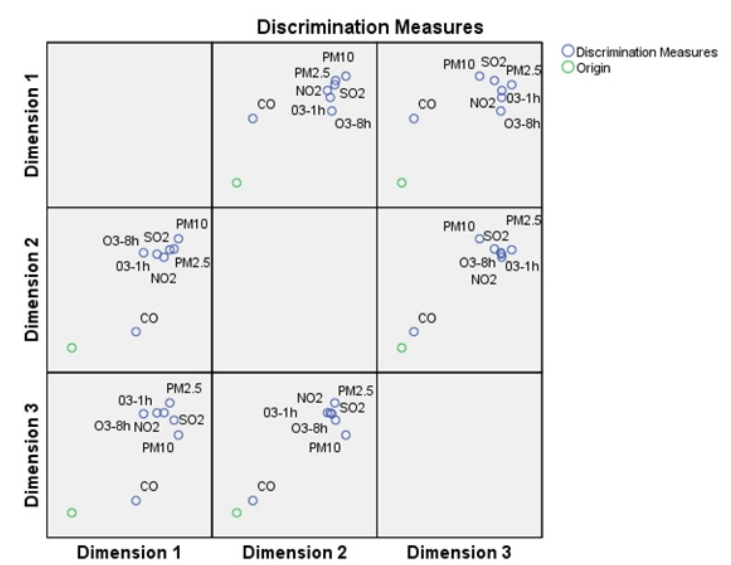

Fig.1 Three-dimensional difference of urban air quality variables

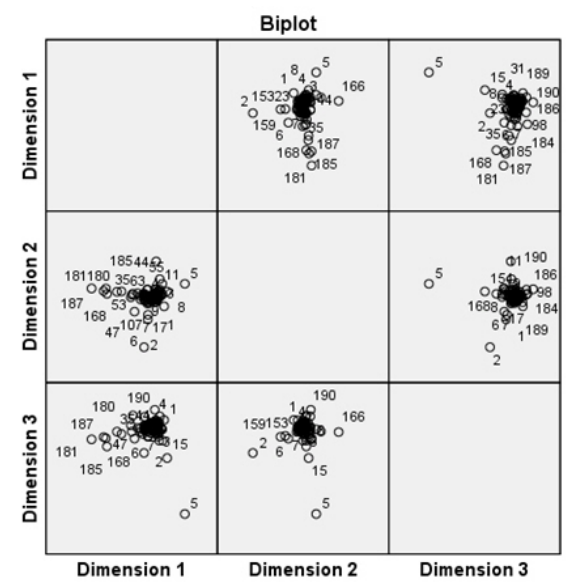

Figure 2 Three-dimensional difference of urban air quality sample points

Figure 2 shows the three-dimensional difference map of urban air quality sample points. Each box shows a two-dimensional difference map of urban samples between two main factors. Each sample point is the city air quality AIRR city ranking point, and the AQI ranking corresponds to cities can be found in Table 4. Cities with AQI ranks 1 to 10 are Sanya, Haikou, Zhanjiang, Maoming, Beihai, Zhuhai, Yunfu, Lhasa, Shenzhen, and Heyuan. From this map, the AIRR city rankings overlap more in the middle of the AIRR rankings, some gaps in the city sample points are the main AIRR ranking points, such as Sanya, Haikou, Zhanjiang, Maoming, Beihai, Zhuhai, etc., or AIRR ranking points, such as Zaozhuang, Linyi, Handan, Tangshan, Hengshui, Baoding, Shijiazhuang, Xingtai, Korla, etc. 


\section{Conclusions and Prospects}

(A)The variable with the greatest impact on air quality is PM2.5, which is also a culprit for people's health. PM10, SO2, and NO2 are also important factors affecting air quality. $\mathrm{CO}$ has limited impact on air quality, and ozone is also an important factor affecting air quality. The state needs to establish the concept of environmental governance for formulate systems, rules and laws, and protect the environment according to the law. It requires to limit the growth rate of urban vehicles and strictly control the emission of pollutants from enterprises.

(B) The comprehensive scores are basically the same as those published by the national air quality index. The cities ranked highest among AQI rankings are Sanya, Haikou, Zhanjiang, Maoming, Beihai, Zhuhai, Lhasa, Shenzhen, Heyuan, Zhoushan and Huizhou. They need supervision to prevent air pollution rebound. The cities ranked high in both AQI rankings and comprehensive scores are Tianjin, Zaozhuang, Linyi, Handan, Tangshan, Hengshui, Baoding, Shijiazhuang, Xingtai, and Korla. Further strengthening the governance of cities and ensuring the effectiveness of governance is needed.

(C) At present, the urban air quality supervision is being strengthened, which is conducive to the discovery of urban environmental pollution sources. Therefore, it is necessary to make full use of monitoring results and take effective measures to govern the environment in accordance with the law. In recent years, the rapid development of urbanization in China's industrialization has caused air pollution, especially smog weather, which is mainly based on PM2.5, and seriously endangers people's health. Industrial development will cause a large amount of energy consumption. At present, energy consumption mainly uses coal. The burning of large amounts of coal will increase carbon emissions, causing dust, $\mathrm{CO} 2$, and $\mathrm{SO} 2$ pollution. Therefore, while reducing energy consumption, we also attach importance to the research, development, and use of green energy, replace green coal with high pollution, reduce carbon emissions, and gradually eliminate or reduce the causes of environmental pollution. The development of urban transportation, the natural evaporation of vehicle oil products and the emission of exhaust gas have also become important killers of urban air pollution, restricting urban automobiles and strict automobile emission standards are effective measures.

\section{Acknowledgements}

This work was a Fund Project: The Ministry of Education Planning Fund Project (17XJA630005);

Sichuan Provincial Department of Education Key Project (17SA0135).

\section{References}

[1] Chen Renjie, Chen Bingheng, Yan Haidong. China's air quality health index preliminary study [J]. Chinese Environmental Science, 2013, 33(11): 2081 2086.

[2] Wang Ju, Hou Jie, Yang Mengxi, Xu Zhiyu, Fang Chunsheng, Chen Kehua, Xiao Zhongshen. Correspondence analysis in the application of atmospheric particle source analysis [J]. China Environmental Monitoring, 2012.6: 41-46.

[3] Zhu Xiuhua, Li Xiaoxu. Application of Correspondence Analysis Method in Urban Atmospheric Environmental Quality Assessment [J]. Journal of Dalian Jiaotong University, 2010.2: 89-93.

[4] Chen Mingyu. Urban Air Quality Evaluation System Based on MATLAB[J]. Ecological Environment Protection, 2013.10: 202-203.

[5] Huang Wenfei, Lu Yiying, Wang Hongxiao, Wen Changling. U.S. Air Quality Management Means Based on Pollution Permits and Its Reference[J]. Environmental Protection, 2014.3: 63-64.

[6] Chen Chun, Research and Exploration of Air Quality in China: Analysis Based on Structural Equation Model [J]. Ecological Economy, 2016.12: 142-145.

[7] (German) Wolfgang Hardle, (by) Leopld Simar, Translated by Chen Shiyi. Applied Multivariate Statistical Analysis [M]. Peking University Publishers, 2011.

[8] Greenacre, M. Correspondence analysis of raw data [J]. Ecology 2010: 91(4): 958-963. 
[9] Leibold, C.Signal-to-noise-optimal scaling of heterogeneous population codes[J].Network 2013: 24(3): 114-128. 